\title{
Effects of Carbon Sources on Pigment Production by Talaromyces purpurogenus LC128689 in Liquid Surface Cultures
}

*Ogbonna, Christiana N.

Department of Plant Science \& Biotechnology,

Faculty of Biological Sciences, University of Nigeria, Nsukka

*Corresponding Author's E-mail: christiana.ogbonna@unn.edu.ng

\begin{abstract}
A pigment producing fungus was isolated from soil collected from cassava processing site in Ebonyi State. The effects of carbon sources on pigment production by the isolate in liquid surface cultures were studied. Pigment production in a basal medium composed of (in $\mathrm{g} / \mathrm{L}$ ) $\mathrm{MgSO}_{4}, 0.4 ; \mathrm{NaNO}_{3}, 0.8$; peptone, 15 mixed with $12 \mathrm{~g} / \mathrm{L}$ of one of the following carbon sources: glucose, Ipomea batatas, Dioscorea alata, Manihot esculenta cratz, Colocasia esculenta flour or soluble starch, was investigated. The highest red, orange and yellow pigment concentrations were obtained with sweet potato and water yam flour, followed by soluble starch while the least pigment concentrations were obtained with glucose. Unit optical densities of red (13), orange (9.5) and yellow (11) pigments were produced by the fungus using Ipomea batatas flour. These were higher than the concentrations of red (9), orange (7) and yellow (10.5) produced from Hajjaj medium composed of (in $\mathrm{g} / \mathrm{L}$ ) Glucose, 50; monosodium glutamate, 12; $\mathrm{K}_{2} \mathrm{HPO}_{4}, 2.5 ; \mathrm{KH}_{2} \mathrm{PO}_{4}, 2.5 ; \mathrm{MgSO}_{4}, 1 ; \mathrm{KCl}, 0.5 ; \mathrm{ZnSO}_{4}, 0.001 ; \mathrm{FeSO}_{4}, 0.001$; and $\mathrm{MnSO}_{4}, 0.001$. The results indicate that Ipomea batatas flour is a better carbon source than glucose for pigment production by $T$. purpurogenus and thus has a very high potential for commercial production of pigments.
\end{abstract}

Key words: Microbial pigments, natural colourants, carbon sources, sweet potato, T. purpurogenus

\section{Introduction}

Pigments are useful compounds with numerous industrial applications. Pigments are used to add colour to processed food (Vendruscolo et al., 2014); they are also used in pharmaceuticals (Visalakchi and Muthumary, 2010), cosmetics, textiles (Sharma et al., 2012, Gupta et al., 2013) and leather dying. Thus, development of methods for production of various pigments will greatly contribute to industrial development of Nigeria, especially the food processing industries. Currently, synthetic pigments are widely used in food industries in Nigeria. However, some of these synthetic pigments have negative health implications and therefore there is a need to revert to natural pigments. Natural food colourants not only improve aesthetic value of our foods but some of them also have desirable characteristics such as preservative and antioxidant properties (Shi et al, 2015).

Although there are various sources of natural pigments such as higher plants, insects, bacteria, algae and fungi, pigment production from microorganisms such as fungi has many advantages over those from higher plants and animals. With microorganisms, less space is required, production is not affected by the weather conditions, cheap feedstock can be used, less effluent is generated and because of the high growth rates, the productivities are in most cases, orders of magnitude higher than the values obtained with higher plants and insects (Nejad and Nejad, 2013).

Pigment production from fungi has become a major focus of fungal research at present because fungi can produce high concentrations of stable diffusible pigments with different colour shades (Afshari et al., 2015, Buhler et al 2015).

Medium components especially carbon sources are of great importance in pigment production. The cost of carbon source comprises about $70 \%$ of the total production costs of most fermentation products (Ogbonna et al 2001). Some of the carbon sources are used as both energy and carbon sources. Thus, reduction in the cost of medium through selection of abundant and cheap carbon sources is a sure method of reducing the cost of production. Consequently, some researchers have investigated the potentials of different agricultural tubers such as sweet potato flour as carbon source for pigment production (Srivastav et al., 2015). Some other researchers have investigated different cheap 
complex carbohydrates including golden brown rice as carbon source for pigment production (Nimnoi and Lumyong, 2011; Yongsmith et al., 2013, Mu et al., 2015).

Surface culture is one of the oldest methods of fungi cultivation, used for production of antibiotics Manteca et al (2008). This is a culture method where the fungus is allowed to germinate, grow and form a mat at the surface of the liquid. Thus, the hyphae are exposed to atmospheric air while they absorb nutrients from the culture broth and excrete metabolites into the culture broth. Although the industrial application of surface culture has reduced because of the problem of scale up and the relatively low productivity, this method is still very important in developing countries because it is very simple, does not require mechanical mixing. Thus after inoculation, power supply is not required during the cultivation. Furthermore, for the extracellular products, the cost of separating the products is low since the mycelia remain on top of the liquid while the product is in the culture broth. This reduces the cost of separation of the product from the biomass which can be very expensive, especially for viscous fungi broths.

In the present study, a pigment-producing fungus was isolated from cassava processing site in Abakaliki, Ebonyi State. It was identified as Talaromyces purpurogenus based on morphological characteristics, microscopic observation and ITS-5.8S rDNA sequence and was assigned the accession number LC128689 (Ogbonna et al., 2017).The effects of some carbon sources on pigment production by the fungus in liquid surface cultures under static conditions is reported.

\section{Materials and Methods}

Microorganism and media components:
Talaromyces purpurogenus LC128689 isolated from soil samples collected from cassava processing site in Abakaliki, Ebonyi State was used in this study. All the carbon sources (except tuber flour), nitrogen sources and mineral salts used in these experiments, unless otherwise stated, were from Wako Pure Chemical Industries Ltd, Japan.

Procurement of tubers: Sweet potato (Ipomea batatas),cassava (Manihot esculenta cratz), cocoyam (Colocasia esculenta) and water yam (Discorea alata) tubers were purchased from New market in Enugu, Enugu State of Nigeria in the month of January, 2015.
Preparation of tuber flour: The tubers were peeled and sliced into thin chips of about $3 \times$ $2 \mathrm{~mm}$ with a circumference of about $0.5 \mathrm{~mm}$ and sun-dried to a constant weight with about $10 \%$ moisture content. They were processed into flour using a clean manual grinding machine. The flour was sieved with cheese cloth and stored in an air tight container in a refrigerator.

\section{Medium preparation and pigment} production: The medium was composed of the following in $(\mathrm{g} / \mathrm{L})$ : Tuber flour, glucose or soluble starch, 12; $\mathrm{MgSO}_{4}, 0.4 ; \mathrm{NaNO}_{3}, 0.8$; and peptone, 15. All the medium components were appropriately weighed and dissolve in appropriate volume of distilled water and dispensed in $100 \mathrm{ml}$ aliquots into $250 \mathrm{~mL}$ Erlenmeyer flasks. The flasks were corked and autoclaved at $121^{\circ} \mathrm{C}$ for $20 \mathrm{~min}$. The flasks were inoculated with active Talaromyces purpurogenus spores $\left(2 \times 10^{7} / \mathrm{mL}\right)$ harvested from 6 days old test tube slants and incubated statically at room temperature $\left(25^{\circ} \mathrm{C} \pm 2^{\circ} \mathrm{C}\right)$. Samples were withdrawn at certain intervals from the culture broth and the optical densities were measured at 400, 460 and $500 \mathrm{~nm}$ respectively for yellow, orange and red pigments according to the method of Cho et al. (2002).

Effects of some tuber flours on pigment production: Flours were prepared from sweet potato (Ipomea batatas), cassava (Manihot esculenta), water yam (Dioscora alata) and cocoyam (Colocasia esculenta) as described above. Twelve grams of each of the flour, glucose, or soluble starch was added to a $100 \mathrm{ml}$ of basal medium containing $0.4 \mathrm{~g} / \mathrm{L}$ of $\mathrm{MgSO}_{4}, 0.8 \mathrm{~g} / \mathrm{L}$ of $\mathrm{NaNO}_{3}$ and $15 \mathrm{~g} / \mathrm{L}$ of peptone in a $250 \mathrm{ml}$ Erlenmeyer flask. The medium was sterilized and inoculated with $T$. purpurogenus spores as described above. Samples were withdrawn intermittently from the culture broth during cultivation to measure the concentration of pigments.

Comparison of pigment production in sweet potato flour medium and a synthetic medium: Pigment production from the sweet potato flour medium was compared with that in a widely used synthetic medium (Hajjaj medium) composed of (in $\mathrm{g} / \mathrm{L}$ ): Glucose, 50; monosodium glutamate, $12 ; \mathrm{K}_{2} \mathrm{HPO}_{4}, 2.5$; $\mathrm{KH}_{2} \mathrm{PO}_{4}, \quad 2.5 ; \quad \mathrm{MgSO}_{4}, 1 ; \quad \mathrm{KCl}, \quad 0.5$; $\mathrm{ZnSO}_{4}, 0.001 ; \mathrm{FeSO}_{4}, 0.001$; and $\mathrm{MnSO}_{4}, 0.001$ (Hajjaj et al., 1997). The experimental conditions were as described above. 


\section{Results and Discussion}

Effects of some carbon sources on pigment production by $T$. purpurogenus

A comparison of the effects of the flours made from tubers (sweet potato (Ipomea batatas), cassava (Manihot esculenta), cocoyam (Colocasia esculenta) and water yam (Dioscorea alata)), glucose and soluble starch on production of yellow, orange and red pigments by $T$. purpurogenus are shown in figures 1,2 and 3 respectively. The fungus grew profusely and produced three colours of pigments in all the flours used. The patterns of yellow pigment production from soluble starch and sweet potato were very similar up to the $9^{\text {th }}$ day. However, by the $12^{\text {th }}$ day, yellow pigment production from sweet potato got higher than that of the soluble starch. It is interesting to note that from the $9^{\text {th }}$ day, yellow pigment production from water yam increased sharply to a value comparable to that obtained with sweet potato. Pigment production from glucose remained very low throughout the cultivation period. In the case of cocoyam, yellow pigment production remained low until after the $9^{\text {th }}$ day when it increased sharply. However, the final value was still lower than the values obtained with other flour (Figure 1).

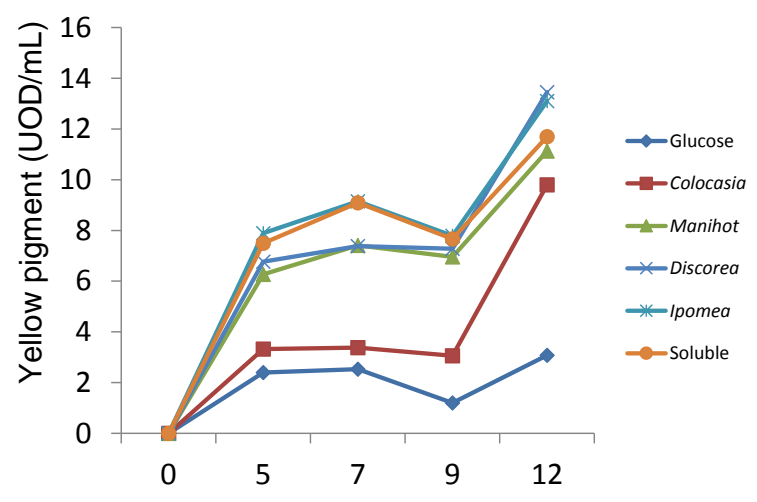

Cultivation time (days)

Fig.. 1: Effects of carbon sources on yellow pigment $(400 \mathrm{~nm})$ production in liquid surface culture.

Time courses of orange pigment production from different flours are shown in Figure 2. The trends in orange pigment production from the different flours were similar to those of the yellow pigments. The highest orange pigment concentration was obtained with sweet potato and water yam. These were followed by soluble starch, cassava and cocoyam while the least was obtained with glucose. In the case of red pigments (Figure 3), the trend was the same as for the orange pigment. The final concentrations of the red pigments $(\mathrm{UOD} / \mathrm{ml})$ were 18 for sweet potato and water yam, 16 for soluble starch, 14.6 for cassava, 11.4 for cocoyam and only 2.8 for glucose. The superiority of sweet potato over other flours is in agreement with the work of Srivastav et al. (2015) who used sweet potato based medium to produce red pigment from Monascus purpureus. Cocoyam starch is known to be relatively difficult to hydrolyze (Omemu et al., 2008) and that may explain why production of the three pigments were very low within the first 9 days of cultivation. However, after 9 days, growth of the fungus increased leading to a corresponding increase in the concentrations of the pigments. On the whole, for each flour used, the concentration of the red pigment was the highest, followed by the orange while the concentrations of the yellow pigments were the least.

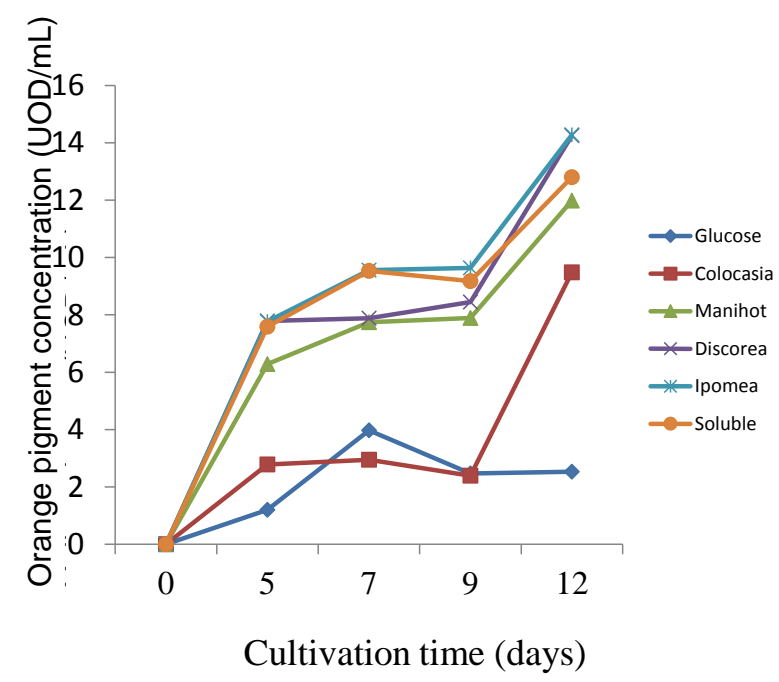

Fig. 2: Effect of carbon sources on orange pigment $(460 \mathrm{~nm})$ production in liquid surface culture.

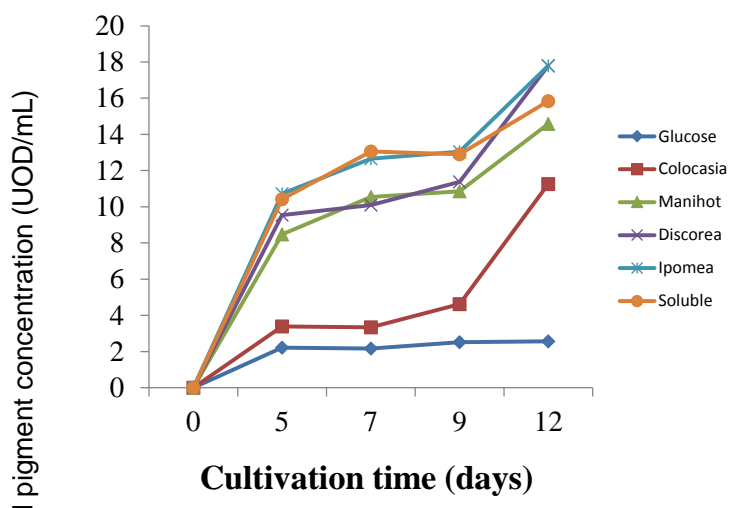

Fig. 3: Effects of carbon sources on red pigment $(500 \mathrm{~nm})$ production in liquid surface culture 
It is interesting to note that the same fungus (Talaromyces purpurogenus) is able to simultaneously produce yellow, orange and red pigments from the same carbon source. Most of the pigments were secreted into the culture broth and only a small percentage remained entrapped in the mycelia. This is very significant in terms of downstream processing. The pigments were easily extracted using ethyl acetate and the extract was recovered by solvent evaporation using a rotary evaporator or simply by pouring the extract into a Petri dish and keeping at room temperature. These colour shades can be used to colour most of our locally produced fabrics, or they can be used in baking industries. However, it is also known that some fungi species produce some toxic substances such as citrinin. Thus, it is necessary to analyse for such toxic substances, and if the current strain produces them, it will be important to investigate culture conditions that will suppress production of toxins, and develop a method of separating the toxins from the pigments.

Comparison of pigment production by $T$. purpurogenus from sweet potato flour medium and Hajjaj medium.

For yellow, orange and red pigments, the concentrations of the pigments produced from potato flour (Figures 4 to 6 ) were significantly higher than those obtained from the Hajjaj medium. In the case of orange (Figure 5) and red (Figure 6) pigments, the concentrations obtained from sweet potato flour were more than two times higher than the values obtained from Hajjaj medium.

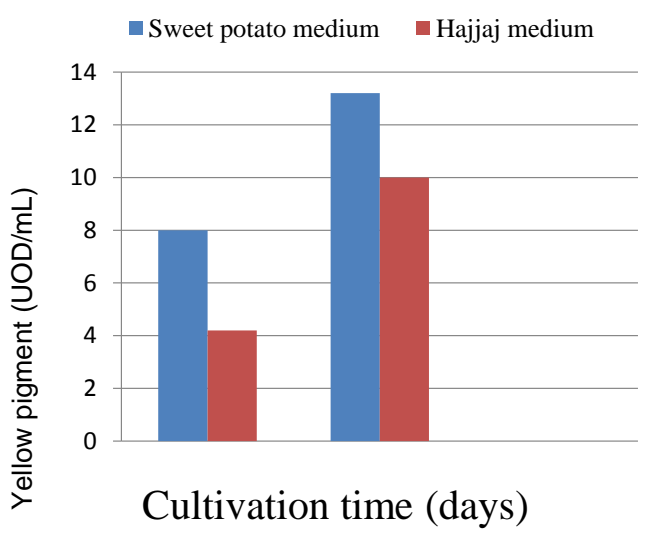

Fig. 4 Comparison of sweet potato flour and Hajjaj media for yellow pigment production by $T$.purpurogenus

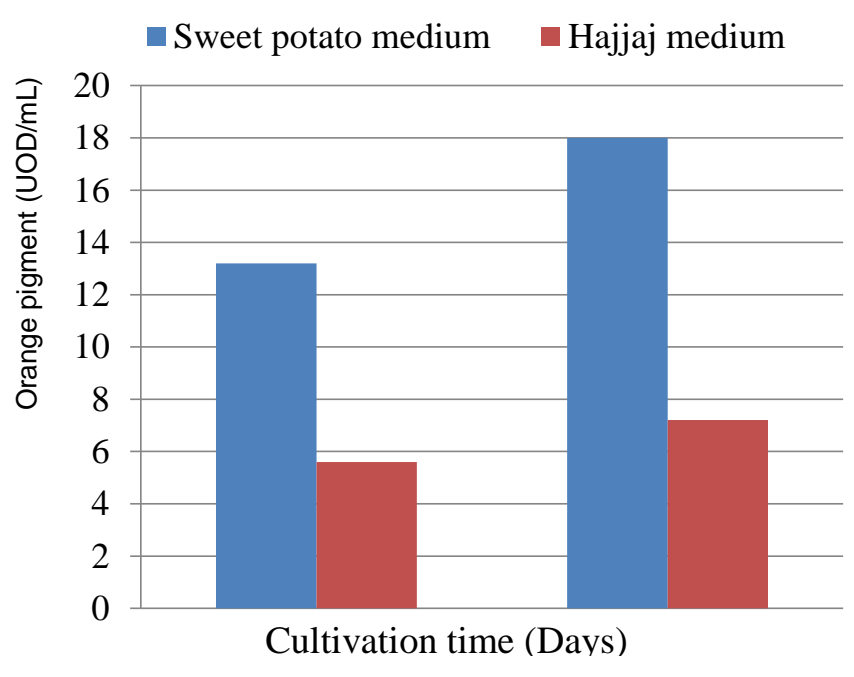

Fig. 5: Comparison of sweet potato flour and Hajjaj media for orange pigment production by T. purpurogenus

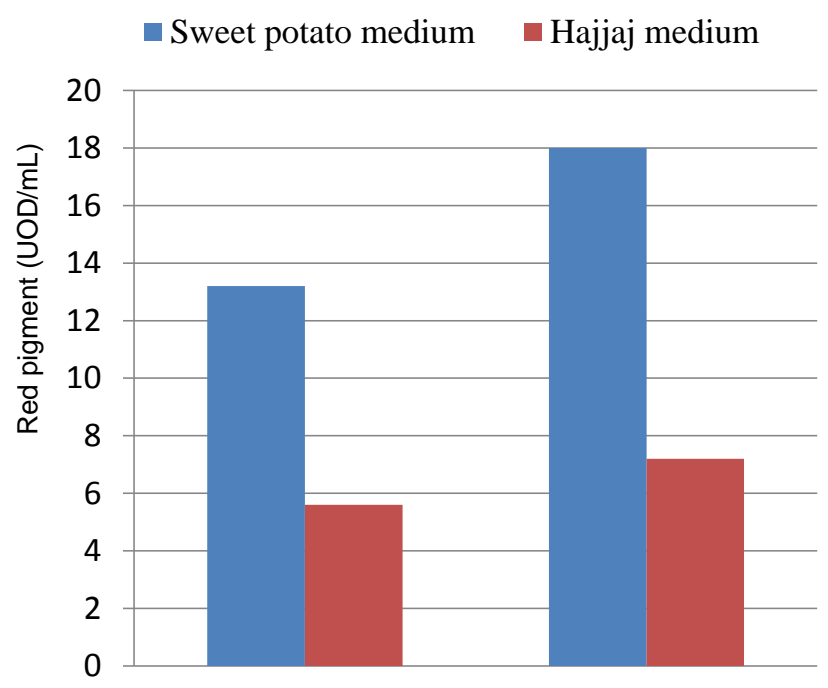

Cultivation time (days)

Fig.. 6: Comparison of sweet potato flour and Hajjaj media for red pigment production by $T$. purpurogenus

One of the limitations of Hajjaj medium is the high cost of the medium. It is therefore very significant that with sweet potato which is cheap and easily available, much higher concentrations of the pigments can be obtained. This demonstrates that sweet potato has a very high potential for commercial production of pigment by this fungus. Using the sweet potato medium, the concentration of the red pigment was the highest, followed by the orange while the least was the yellow pigments. On the other hand, the Hajjaj 
medium gave the highest concentration of yellow pigment, followed by the red while the orange pigment was the least. This implies that the choice of the medium depends on the target pigment. Nevertheless, considering the cost of the medium, it is recommended that sweet potato medium be used for efficient pigment production by this strain.

\section{Conclusion}

The results of this study have shown that the fungus Talaromyces purpurogenus is capable of utilizing complex carbohydrates such as flour from agricultural tubers (sweet potato, water yam, cassava and cocoyam) for simultaneous production of yellow, orange and red pigments. These are cheaper carbon sources than glucose and other monosaccharides. Among the tubers, sweet potato was the best for the production of the three (yellow, orange and red) pigments. With sweet potato medium, much higher pigment concentrations were obtained compared with the widely used Hajjaj medium. Since sweet potato medium is very cheap compared with Hajjaj medium, its use for commercial production of pigments will significantly reduce the cost of production since the cost of medium comprises as high as $70 \%$ of the total cost of production of most metabolites.

\section{Conflict of Interest}

There is no conflict of interest regarding the manuscript.

\section{References}

Cho, Y. J., Park, J. P., Hwang, H. J., Kim, S. W., Choi, J. W., Yun, J. W. (2002). Production of red pigment by submerged culture of Paecilomyces sinclairii. Lett. Appl. Microbiol., 35:195202.

Gupta, C., Sharma, D., Aggarwal, S. and Nagpal, N. (2013). Pigment production from Trichoderma for dyeing of silk and wool. International Journal of Science and Nature, 4 (2) 351-355.

Hajjaj, H., Klaebe, A., Loret, M. O., Tzedakis, T., Goma, G. and Blanc, P. J. (1997). Production and identification of $\mathrm{N}$ glucosylrubropunctamine and $\mathrm{N}$ glucosylmonascorubramine from Monascus ruber and occurrence of electron donor-acceptor complexes in these red pigments. Appl. Environ. Microbiol. 63: 2671-2678.
Manteca, A., Alvarez, R., Salazar N., Yague P. and Sanchez, J. (2008). Mycelium differenciation and antibiotic production in submerged cultures of Streptomyces coelicolor. Applied and Environmental Microbiology, 74 (12): 3877- 3886.

Mu, H., Liubin, H., Xuemei, D. and Shuxin, Z. (2015). Influence of different substrates on the production of pigments and citrinin by Monascus FJ46. Advances in Applied Biotechnology, 332: 257- 264.

Nejad, H. E. and Nejad, A. E. (2013). Cochineal (Dactylopius coccus) as one of the most important insects in industrial dyeing. International Journal of Advanced Biology and Biomedical Research, 1(11): 1302-1308.

Nimnoi, P. and Lumyong, S (2011). Improving solid-state fermentation of Monascus purpureus on agricultural products for pigment production. Food and Bioproc. Technol., 4(8): 1384-1390.

Ogbonna, J. C., Mashima, H. and Tanaka, H. (2001). Scale up of fuel ethanol production from sugar beet juice using loofa sponge immobilized bioreactor. Bioresource Technology, 76: 1-8.

Ogbonna, C. N., Aoyagi, H. and Ogbonna, J. C. (2016). Isolation, identification and preliminary studies on pigment production potentials of Talaromyces purpurogenus in solid state cultures. African Journal of Biotechnology, 16(13): 672-682.

Ogbonna, C. N. (2016). Production of food colourants by filamentous fungi. A Review. African Journal of Microbiology Research, 10 (26): 960971.

Omemu, A. M., Bankole, M. O. and Akpan, I. (2008). Production and characterization of extracellular amyloglucosidase from Aspergillus niger CA-19 by solid state fermentation. Research Journal of Microbiology, 3: 129-136.

Sharma, D., Gupta, C., Aggarwal, S. and Nagpal, N. (2012). Pigment from fungus for textile dyeing. Indian $\mathrm{J}$. Fibre Text. Res., 37: 68-73. 
Shi, K., Song, D., Chen, G., Pistolozzi, M., Wu, Z. and Quan, L. (2015). Controlling composition and colour characteristics of Monascus pigments by $\mathrm{pH}$ and nitrogen sources in submerged fermentation. J. Biosci. Bioeng. 120(2): $145-154$.

Srivastav, P., Vivek, K. Y., Sharmila, G., Muthukumara and Chandrasekara (2015). Red pigment production by Monascus purpureus using sweet potato-based medium in submerged fermentation. Nutrafoods, 14 (3): 159167.

Vendruscolo, F., Tosin, I., Giachini, A. J., Schmidell, W. and Ninow, J. L. (2014). Antimicrobial activity of Monascus pigments produced in submerged fermentation. Journal of Food Processing and Preservation, 38(4): 1860-1865.

Visalakchi, S. and Muthumary, J. (2010). Antimicrobial activity of the new endophytic Monodictys castaneae SVJM139 pigment and its optimization. Afr. J. Microbiol. Res., 4 (1): 038-044.

Yongsmith, B., Thongpradis, P., Klinsupa, W., Chantrapornchai, W. and Haruthaithanasan, V. (2013). Fermentation and quality of yellow pigments from golden brown rice solid culture by a selected Monascus mutant. Appl. Microbiol. Biotechnol., 97: 8895- 8902. 